Conference Article

\title{
On the visualization of joint formation during linear friction welding
}

\author{
A.T. Bikmeyev ${ }^{1}$, R.K. Gazizov ${ }^{1}$, A.M. Yamileva ${ }^{1}$, A. Vairis $^{2}$ and F.O. Zheleznov ${ }^{1}$ \\ ${ }^{1}$ Ufa State Aviation Technical University, Ufa, Russia \\ ${ }^{2}$ Technological Education Institute of Crete, Heraklion, Greece
}

Received 2 September 2015; Accepted 12 September 2015

\begin{abstract}
A 3D computer model of the preliminary and the transition phases of LFW using ANSYS was developed. Based on the adhesion phenomena theory, we introduce a simple method to evaluate the areas of joint formation. Results of this evaluation are in good agreement with experiments. Custom software for the 3D-simulation of the process of joint formation and material movement into the flash was built, which used the results of the FEM model.
\end{abstract}

Keywords: Linear friction welding, visualization, adhesion, finite element method, ANSYS Multiphysics.

\section{Introduction}

Linear friction welding (LFW) is a solid-state process for joining metals, plastics and other materials [1-2]. Despite the apparent simplicity of this welding process the actual physical processes occurring during its cycle are quite complex, with the most difficult being the speed of its development. There are many papers with results of modeling LFW using finite elements, but the majority of them describes the process before [3-5] or after the joining has completed [6-9]. There are very few works on the simulation of the process of joining welded parts. And such papers do not use the finite element method (FEM), but particle methods [10], which do not take into account the temperature and pressure changes that occur during the process and which are dramatic for the short process time.

In this paper we propose a simple method to determine the areas of joint based on the adhesion theory which also assists in the visualization of the process of joint formation to provide a better understanding of this dynamic process. Following this results are compared with experiments.

Another problem with computer simulation is absence of lightweight and useful tools to visualize the results of modeling without the FEM software. There are many engineering software suites for the finite element simulation of physical processes in different areas, but all of them are quite expensive and very demanding. This can be a problem when you need to show modelling results at different places (at conferences, at factories or at a design agency) where there is no such software installed.

\footnotetext{
*E-mail address: bikmeyev-at@ugatu.su ISSN: 1791-2377 @ 2015 Kavala Institute of Technology. All rights reserved.
}

FEM packages have a special facility, called the postprocessor, for visualizing the results of simulations. A few of them have a rich set of capabilities to make complex calculations with the result data. Nevertheless in some cases it is more useful to develop special software to process the results of computer simulation with special 3D-packages like 3D Max or with 3D-engine-like Unity. They are software with a simplified interface or with ability to process existing data (for example, without requiring a license for the modeling system), to employ additional functions etc.

Using a third party software to postprocess is appropriate to join or to combine results of different simulations in one viewport in order to compare them and identify differences and similarities. In the second part of this paper we will introduce special software, which uses the 3D-engine Unity [11] to visualize results of the numerical modeling of linear friction welding $[1,12]$ in ANSYS Mechanical [13].

\section{Visualization of the joint formation process}

The general form of the Amontons-Coulomb law for friction force is well established $[14,15]$ :

$$
F_{f r}=\mu N+A
$$

where $\mu$-is the coefficient of friction, $N-$ it the normal load (or reaction force) and $A$ - is a constant which characterizes adhesion. At low temperatures and small loads, adhesion is very weak and usually we can see a shorter version of the friction law - without the adhesion constant. But during LFW there are high temperatures and stresses (above $1000^{\circ} \mathrm{C}$ and more than $300 \mathrm{MPa}$ for Ti-alloys) at the welding interface, and the complete form of the friction law is required. With regards to the FEM model it requires as table 
of values of the friction coefficient $\mu$ at various temperatures.

But to model the adhesion using FEM we need to develop algorithms of dynamic reconstruction of the mesh with joining and breaking different parts of two meshes of the two oscillating parts. This is very difficult and requires low level programming of the FEA software.

We therefore have introduced an algorithm, which uses mathematical conditions to describe dry contact friction as well as internal friction. Dry contact friction take place for the following condition [15-16]:

$$
\frac{\partial \sigma_{\text {cut }}}{\partial \mathbf{n}}>0
$$

where $\sigma_{\text {cut }}$ is the cutting (shear) stresses in the contact area, $\mathbf{n}$ is a normal to the contact surface. In other words, when a cutting force on the contact surface exceeds stresses in the bulk of the sample, then there is dry friction. In the opposite case of extensive material destruction the friction force increases. It is time when adhesion phenomena are found to occur. Then the condition to develop adhesion is [16]:

$$
\frac{\partial \sigma_{\text {cut }}}{\partial \mathbf{n}}<0
$$

In order to investigate where a joint begins to form and how it develops with time, then results of the FE analysis in ANSYS software, and in particular the stress component in the moving direction, are brought in. The finite difference method is used to calculate the gradient in each node on the contact surface subject to condition (2).

A FEM model of the preliminary and transitional stages of LFW with ANSYS Mechanical was built. Results of the

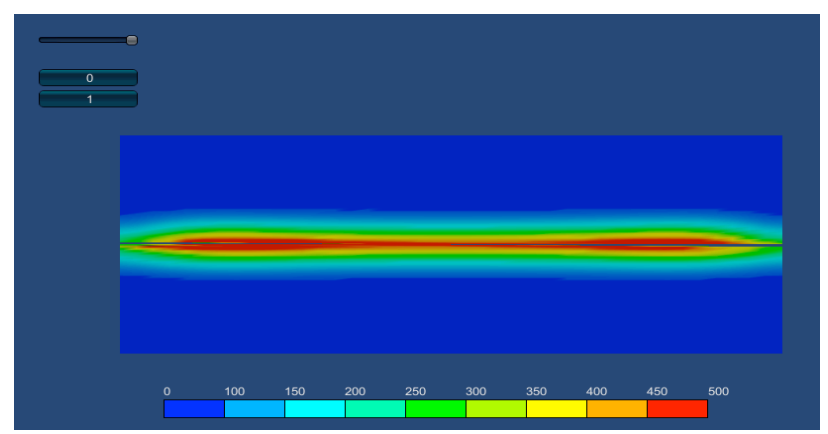

(a)

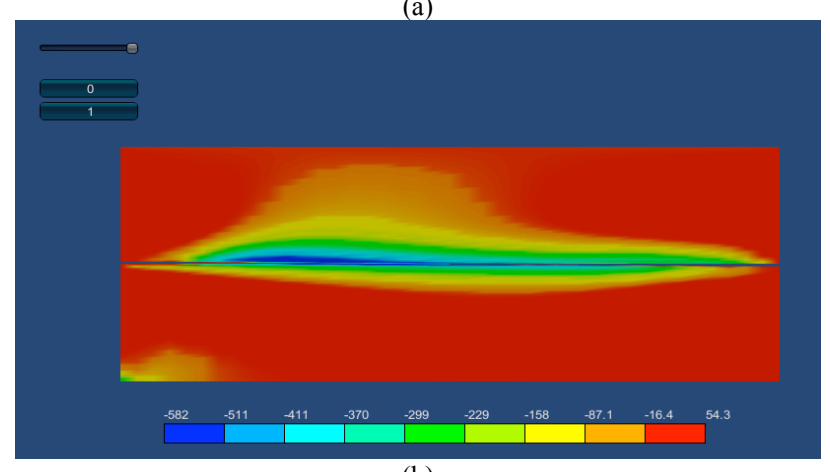

(b)

Fig.1. Visualization of LFW process of two sample of Ti-6Al-4V. The state after $0.225 \mathrm{~s}$. from the beginning of the process is shown: (a) temperature distribution; (b) distribution of stress in the direction of the sample movement. simulations were saved as plain text and visualized with a $3 \mathrm{D}$ software developed in our group. Figure 1 shows the temperature and stress distributions in the centre area of a $3 \mathrm{D}$ sample. There is an asymmetric aspect of the variable distributions.

Then using this software the gradient of the in-plane stresses was calculated and results are shown in Figure 2. Areas in which condition (2) applies are shown with red. At the bottom of figure 2 the actual contact area of a sample is shown [7]. This photo was obtained when the experiment was stopped to study the incomplete joining. The welding process was stopped after 14 oscillations $(\sim 0.28 \mathrm{~s}$.) and tested with a three-point bend test. It can be seen that the actual adhesion develops at the central part of the sample, away from its edges. There is very good agreement of the numerical and experimental results.

Schroder and others suggested that this is probably because of the higher temperatures developing there at the early stages of the process [7]. The same results were reached in our previous papers using mathematic modelling for a $2 \mathrm{D}$ case $[17,18]$. As we can see from Fig.1 this hypothesis is fully confirmed.

It is therefore fair to say that the developed FEM model of LFW and the proposed method to determine areas of initial adhesion are adequate to represent actual phenomena.

\section{Visualization of the FEM simulation results for LFW process models}

In order to visualize the results of the simulations in $3 \mathrm{D}$, we have developed an algorithm to post process datafiles from the FEA package, and have built an application with the engine Unity v.4.x.

Unity is software for creating $3 \mathrm{D}$ program components of interactive entertainment or multimedia experience [4]. It provides a display of 3D scenes and 3D objects in real-time. More over, this $3 \mathrm{D}$-engine has an interface to projection
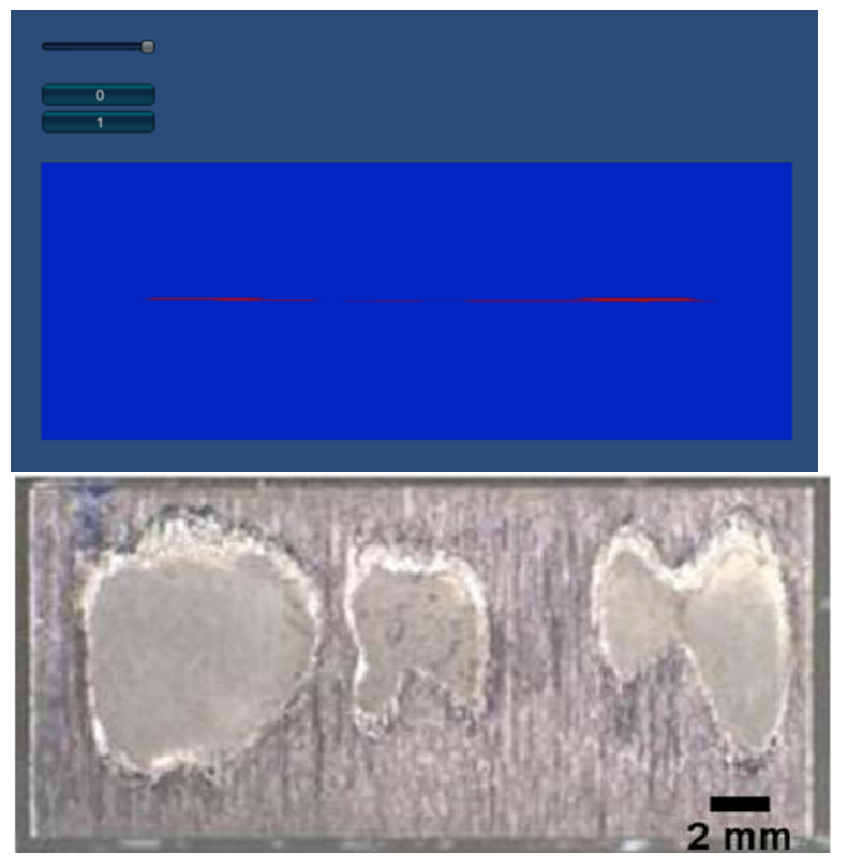

Fig.2. Visualization of adhesion areas and comparison with experiments [7]. 
equipment of virtual reality class CAVE (Computer-Aided Virtual Environment). This virtual reality room is part of the laboratory GAMMETT (http://gammett.ugatu.su/) of Ufa State Aviation Technical University and it is actively used by researchers to visualize results of their models.

As an example of the visualization of complex models we chose the model with discrete steps of layer elimination in ASNYS Mechanical. The welded samples have a rectangular shape with dimensions $26 \mathrm{~mm} \times 13 \mathrm{~mm} \times 5 \mathrm{~mm}$. The height of the actual samples is about $35 \mathrm{~mm}$, but in the model a part of the real samples is studied which corresponds to the heat affected zone and the high stress zone only, of about $5 \mathrm{~mm}$ in height from the contact area.

In order to avoid the numerical difficulties introduced by the large plastic deformations a simplified FE model of the thermo-elastic deformation of two samples during LFW with an elimination of material layers into the flash in the contact area based on a specified criterion was been developed $[4,12]$. The stepwise elimination of a material layer is performed by transferring the temperature field to the chosen thickness, without actual removing the finite elements and altering the stress field. Hence, a set of calculations were performed in ANSYS with control from an APDL script [13].

Due to this discrete step simulation computation becomes stable and allows for some improvements of the model during simulation like mesh or geometry adaptivity. Interpolation tools let us eliminate a material layer of any thickness and to store the reduced amount of data in areas with small gradients. But this approach make it impossible to represent modeling results using the ANSYS post processing facilities. Then new software provides this alternative to show results of the analysis.

Visualization is represented as a cuboid with a polygon mesh with color nodes for temperature, velocity, stress etc from the results' database.

Using datafiles with temperature and velocity fields of samples and information about the eliminated layer on every step (see previous paper in this special issue), the visual model of LFW with the history of temperature in the samples and that of shortening was developed. Input files to form the visual model are the results tables in text format in defined points of geometry, which were calculated with ANSYS during modeling.

So the visual model can be constructed before the calculation stage and then can be completed using the results data. This visual model is not dependent on the type of FE solver but only on model parameters, and can be used with any FE software.

The process of flash formation was represented following the principle of the conservation of volume. Its length along each side was calculated while taking into account the volume of the eliminated layers.

In order to correctly simulate flash formation, the developed visual model employs coefficients which define the form of flash and its rate of grow along the direction of movement and perpendicularly to it.

The visual model (see a figure 3) was built for LFW of titanium alloys. In this case the rectangular form of flash was used, which is a first order approximation.

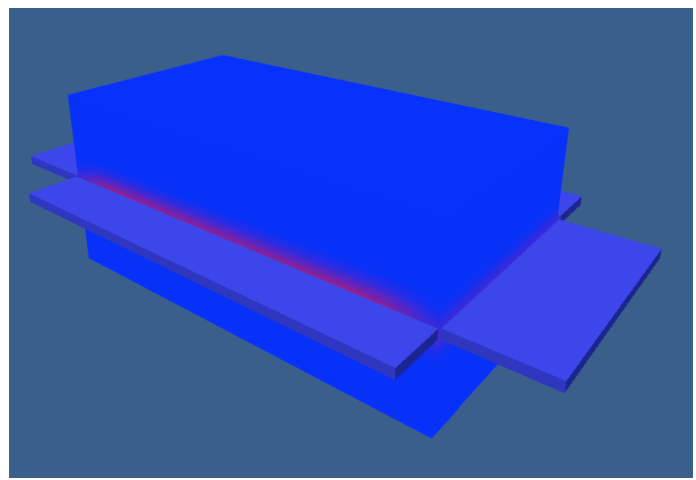

(a)

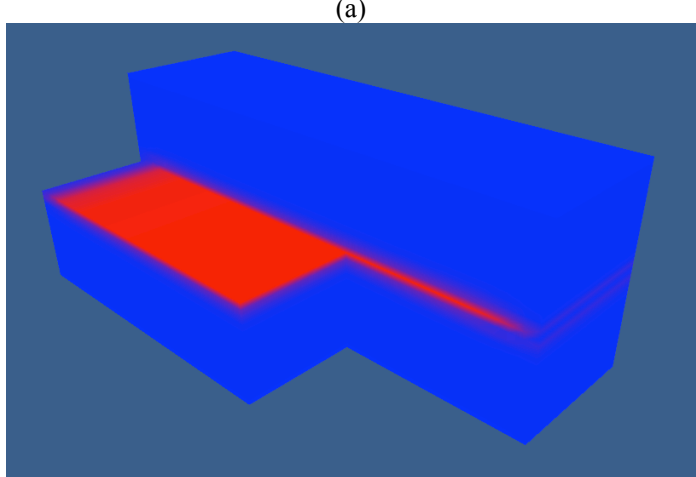

(b)

Fig. 3. Visual model of LFW: a) with flash, b) without flash, half of upper sample, three quarters of lower one being visible

This model allows to investigate results inside the part as well as other visualization tools for the analysis of fields. Information about field values from simulation is shown with colors with the classic rainbow legend. The nonuniform scale is used because of the very steep gradients present in the contact zone of the LFW process.

\section{Conclusions}

The following are the results of this work:

1. Using adhesion theory a new simple method to evaluate areas of initial joint formation is introduced. Results of simulation with this method shows good agreement with experiments.

2. For detailed study of the computer simulation results, the visualization model was formed using the Unity 3D-engine. Using this model it was possible to review the simulation results not only on plots but with $3 \mathrm{D}$ animated images.

3. The visualization software was used to present results of the LFW simulation using a stepwise elimination of material layers.

\section{Acknowledgments}

This work was supported by a grant of the Government of Russian Federation through Resolution No. 220, Agreement No. 11.G34.31.0042. 


\section{References}

[1] A.Vairis, M.Frost. "On the extrusion stage of linear friction welding of Ti6A14V”, Material Science and Engineering, A271, pp. 477484, 1999.

[2] A. Vairis, "The development of a continuum framework for friction welding processes with the aid of micro-mechanical parameterisations", Int. J. Modelling, Identification and Control, vol. 2, No. 4, pp.346-355, 2007.

[3] Wenya Li, Feifan Wang, Shanxiang Shi, and Tiejun Ma, "Numerical Simulation of Linear Friction Welding Based on ABAQUS Environment: Challenges and Perspectives", Journal of Materials Engineering and Performance, vol.23, no.2, pp.384-390, 2014.

[4] J. Sorina-Müller, M. Rettenmayr, D. Schneefeld, O. Roder, W. Fried, "FEM simulation of the linear friction welding of titanium alloys", J. Computational Materials Science, vol.48, pp.749-758, 2010.

[5] Mica Grujicic, G. Arakere, B. Pandurangan, C.-F. Yen, and B.A. Cheeseman, "Process Modeling of Ti-6Al-4V Linear Friction Welding (LFW)", Journal of Materials Engineering and Performance, vol.21, issue 10, pp.2011-2023, 2012.

[6] R. Turner, R.M. Ward, J-C. Gebelin and R.C. Reed, "Linear friction welding of Ti-6Al-4V: Modelling and validation", Acta Material, vol.59, issue.10, pp. 3792-3803, 2011.

[7] F. Schroder, R.M. Ward, A.R. Walpole, R.P. Turner, M.M. Attallah, J.-C. Gebelin and R.C. Reed Linear friction welding of Ti6A14V: experiments and modeling // Materials Science and Technology, vol.31, Is. 3 (February 2015), pp. 372-384.

[8] Anthony R. McAndrew, Paul A. Colegrove, Adrian C. Addison, Bertrand C.D. Flipo, Michael J. Russell, "Modelling the influence of the process inputs on the removal of surface contaminants from Ti-6Al-4V linear friction welds", Materials and Design, vol. 66, pp. 183-195, 2015.

[9] Anthony R. McAndrew, Paul A. Colegrove, Adrian C. Addison, Bertrand C.D. Flipo, Michael J. Russell, Lucie A. Lee "Modelling of the workpiece geometry effects on Ti-6Al-4V linear friction welds", Materials and Design, vol. 87, pp. 1087-1099, 2015.

[10] Changbao Song, Tiesong Lin, Peng He, Zhen Jiao, Jun Tao, Yajuan Ji, "Molecular dynamics simulation of linear friction welding between dissimilar Ti-based alloys", Computational Materials Science, vol.83, pp. 35-38, 2014.

[11] Unity Manual on http://docs.unity3d.com/Manual/

[12]S.K. Kiselyeva, A.M. Yamileva, M.V. Karavaeva, I.Sh. Nasibullayev, V.M. Bychkov, A.Yu. Medvedev, A.V. Supov, F.F. Musin, I.V. Alexandrov, V.V. Latysh. "Computer modeling of linear friction welding based on the joint microstructure", Journal of engineering science and technology review, vol.5, Issue 3, pp. 44-47, 2012.

[13] ANSYS Help. ANSYS Inc. Release 15.0, 2013.

[14] B.Brushan Modern Tribology Handbook, Volume One: Principles of Tribology. CRC Press LLC, 2001.

[15] I.V.Kragelsky Friction Wear Lubrication: Tribology Handbook (Volume 1). Pergamon, 1982.

[16] I.V.Kragelsky, I.E. Vinogradova Friction coefficients. Moscow: Mashgiz, 1962. [in Russian]

[17] A.T. Bikmeyev, A.M. Yamileva, A. Vairis, R.K. Gazizov "Mathematical and Numerical Models of the Preliminary Phases of the Linear Friction Welding Process", Woodhead Publishing Limited, Proceedings of the International Joint Symposium on Joining and Welding IJS-JW 2013, 6-8 November, Osaka, Japan. pp.299-304, 2013.

[18] A.T. Bikmeyev, R.K. Gazizov, A. Vairis, A.M. Yamileva "Modelling the temperature distribution in the contact area of a moving object in case of linear friction welding", ASME 2013 International Mechanical Engineering Congress and Exposition Volume 8A: Heat Transfer and Thermal Engineering. San Diego, California, USA, November $15-21,2013 .-8$ p. ISBN: 978-07918-5634-5 